\title{
High-time resolution conjugate SuperDARN radar observations of the dayside convection response to changes in IMF $B_{y}$
}

\author{
G. Chisham ${ }^{1}$, M. Pinnock ${ }^{1}$, A. S. Rodger ${ }^{1}$, J.-P. Villain ${ }^{2}$ \\ ${ }^{1}$ British Antarctic Survey, Natural Environment Research Council, Cambridge, UK \\ e-mail: G.Chisham@bas.ac.uk \\ ${ }^{2}$ LPCE/CNRS, Orléans, France
}

Received: 9 July 1999 / Revised: 15 September 1999 / Accepted: 16 September 1999

\begin{abstract}
We present data from conjugate SuperDARN radars describing the high-latitude ionosphere's response to changes in the direction of IMF $B_{y}$ during a period of steady IMF $B_{z}$ southward and $B_{x}$ positive. During this interval, the radars were operating in a special mode which gave high-time resolution data $(30 \mathrm{~s}$ sampling period) on three adjacent beams with a full scan every $3 \mathrm{~min}$. The location of the radars around magnetic local noon at the time of the event allowed detailed observations of the variations in the ionospheric convection patterns close to the cusp region as IMF $B_{y}$ varied. A significant time delay was observed in the ionospheric response to the IMF $B_{y}$ changes between the two hemispheres. This is explained as being partially a consequence of the location of the dominant merging region on the magnetopause, which is $\sim 8-12 R_{E}$ closer to the northern ionosphere than to the southern ionosphere (along the magnetic field line) due to the dipole tilt of the magnetosphere and the orientation of the IMF. This interpretation supports the anti-parallel merging hypothesis and highlights the importance of the IMF $B_{x}$ component in solar wind-magnetosphere coupling.
\end{abstract}

Key words: Ionosphere (plasma convection) Magnetospheric physics (magnetopause, cusp, and boundary layers; solar wind - magnetosphere interactions)

\section{Introduction}

One of the most important challenges in physics involves understanding the process of magnetic reconnection. Reconnection plays a major role in the transfer

Correspondence to: G. Chisham of energy and momentum between the solar wind, the magnetosphere and the ionosphere. The consequences of reconnection are particularly relevant to the cusp region of the magnetosphere where magnetic field lines from the ionosphere connect directly to the boundary of the magnetosphere and where shocked solar wind plasma has ready access to the upper atmosphere (see Smith and Lockwood, 1996 for a recent review of cusprelated science). Reconnection is the major contributor to the global magnetospheric convection process. Measurement of this convection process in the ionosphere provides an insight into the global magnetospheric processes. The convection pattern observed in the dayside, high-latitude ionosphere is strongly influenced by the direction of the interplanetary magnetic field (IMF) in the solar wind. The $B_{z}$ component of the IMF is the key parameter which determines the amount of open flux in the magnetosphere and the overall magnitude of the internal flow. Reconnection is enhanced on the dayside magnetopause when the IMF has a southward $\left(B_{z}<0\right)$ component, oppositely directed to the Earth's geomagnetic field. Under this condition a two cell convection pattern is established in the ionosphere. When $B_{z}<0$, the $B_{y}$ component has a considerable influence on the relative sizes of the two convection cells found on the dawn and dusk sides of the magnetosphere as well as the direction of the highlatitude convection and the location of the convection reversal boundary (e.g. Heppner and Maynard, 1987; Cowley et al., 1991). When $B_{y} \neq 0$, the curvature in newly opened field lines is subject to a magnetic tension force with a component in the $y$ direction. For $B_{y}>0$, the field lines in the Northern (Southern) Hemisphere are pulled towards dawn (dusk). For $B_{y}<0$, the orientation of these flows are reversed (e.g. Greenwald et al., 1990). The picture ordered by $B_{z}$ is rather simplistic, and two cell convection patterns are also observed when $B_{z}$ is positive but $B_{y}>B_{z}$ (e.g. Freeman et al., 1993). This implies low-latitude reconnection, but at sites far displaced from the subsolar point. 
The most comprehensive studies of the variations in ionospheric convection for different IMF conditions have presented statistical/averaged patterns describing each IMF state (e.g. Heelis, 1984; Friis-Christensen et al., 1985; Heppner and Maynard, 1987; Senior et al., 1990; Rich and Hairston, 1994; Weimer, 1995; Ruohoniemi and Greenwald, 1996). These studies have confirmed theoretically predicted variations in dayside convection (e.g. Crooker, 1979; Cowley, 1981; Reiff and Burch, 1985) and have given considerable insight into the role of the IMF. However, it is important to remember that the observed patterns are generally averaged to a high degree and present a time-stationary average picture. The observational task is made difficult since the actual convection pattern can vary greatly at times from the predicted statistical/averaged one because of smaller-scale electric field fluctuations in the magnetosheath and ionosphere. To study temporal changes in ionospheric convection, comparison needs to be made with models that suggest how ionospheric convection responds to these changes. Cowley and Lockwood (1992) discuss the general concepts concerning the excitation of ionospheric convection and consider how patches of newly opened flux and their associated flows evolve with time following a burst of magnetopause reconnection. Their model envisages reconnection commencing at the ionospheric footprint of the magnetopause reconnection $\mathrm{x}$-line (sometimes known as the merging gap, Moses et al., 1987) near magnetic local noon and spreading tailward. Observations suggest that the speed of this tailward expansion is between 1 and $10 \mathrm{kms}^{-1}$ depending on the magnetic local time of observation (e.g. Lockwood et al., 1986; Todd et al., 1986; Etemadi et al., 1988; Saunders et al., 1992). However, the speed of the global ionospheric response to IMF changes is a matter of current debate. Recently, Ridley et al. (1998) and Ruohoniemi and Greenwald (1998) have reported measurements which have been interpreted as showing a near-instantaneous global change of the ionospheric convection pattern. The correct interpretation is still a matter for discussion (Lockwood and Cowley, 1999; Ridley et al., 1999).

As yet, no studies have illustrated temporal differences in the ionospheric convection response between the Northern and Southern Hemispheres. We present hightime resolution data from SuperDARN HF radars in both the Northern and Southern Hemispheres which describe the high-latitude ionospheric response in the cusp region to changes in the $B_{y}$ component of the IMF on 8 May, 1998. SuperDARN radars in both hemispheres allow us to make conjugate measurements of convection velocity vectors. The high-temporal resolution allows us to observe for the first time a time delay between the response in the Northern and Southern Hemispheres. We discuss this time delay in terms of the expanding phase front of the signal in the ionosphere and of the predicted location of the dominant reconnection site on the magnetopause considering the dipole tilt of the magnetosphere and the orientation of the IMF.

\section{Instrumentation}

SuperDARN (The Super Dual Auroral Radar Network) is a network of coherent scatter HF radars (Greenwald et al., 1995) which measures backscatter from fieldaligned decametre-scale ionospheric irregularities. The transmitted HF radar signals are refracted towards the horizontal as they enter ionospheric regions with higher electron densities. If these regions contain ionospheric irregularities, the radar signals will be backscattered when they are propagating perpendicular to the magnetic field. In the high-latitude ionosphere, these ionospheric irregularities are often present (Tsunoda, 1988). The irregularities move with the background plasma drift at F-region altitudes (Villain et al., 1985; Ruohoniemi et al., 1987) and so provide information about large-scale convection-related processes in the radar field-of-view. The SuperDARN radars are therefore a very good diagnostic tool for studies of magnetosphereionosphere coupling. The radars transmit power at a fixed frequency in the range $8-20 \mathrm{MHz}$ and from the return signals an estimate of the variation in backscatter power, line-of-sight Doppler velocity and spectral width in the radar field-of-view is derived (see Baker et al., 1995 for details). Many of the SuperDARN radars have overlapping fields-of-view which allow the estimation of field-perpendicular velocity vectors.

This study uses high-time resolution data from three of the SuperDARN radars, Iceland West (Stokkseyri) in the Northern Hemisphere and Halley and Sanae in the Southern Hemisphere. Data from the Goose Bay radar in the Northern Hemisphere are also used to derive velocity vectors. The Iceland West radar is located in the southwest of Iceland $\left(63.9^{\circ} \mathrm{N},-21.0^{\circ} \mathrm{E}\right)$ and its central beams point $59^{\circ}$ west of true north. The radar scan sweeps through 16 beam positions differing by $3.25^{\circ}$. At the time of the present study, the radar was operating in a special mode where each beam of a normal scan was interspersed by one of three high-resolution beams, 7,8 , and 9 . The dwell time of $5 \mathrm{~s}$ on each beam produced a full scan in $3 \mathrm{~min}$ and each of the high-resolution beams repeated every $30 \mathrm{~s}$. In each beam, 75 range gates were used with a pulse length of $300 \mu s$ (equivalent to $45 \mathrm{~km}$ ) and a lag to the first range of $1200 \mu s(180 \mathrm{~km})$. The Halley radar located at Halley, Antarctica $\left(75.5^{\circ} \mathrm{S}\right.$, $-26.6^{\circ} \mathrm{E}$ ), transmits towards the geomagnetic South Pole. The operational characteristics at Halley were similar to those at Iceland West; the three high-resolution beams being beams 2, 3, and 4 which are directed over the geographic South Pole. Also located in Antarctica is the Sanae radar $\left(72.0^{\circ} \mathrm{S},-3.0^{\circ} \mathrm{E}\right)$ which shares a large common field-of-view with the Halley radar. Most of the operational characteristics of the Sanae radar were the same as at Halley; the high-resolution beams being beams 4, 5, and 6. However, the dwell time at Sanae was longer at $7 \mathrm{~s}$ leading to a full scan time of $4 \mathrm{~min}$ and a repeat time of the high-resolution beams of $42 \mathrm{~s}$.

Figure 1 displays the fields-of-view of the highresolution beams from the three radars for the range gates where backscatter was observed. The geometry of the field-of-view was different for each of the radars, 


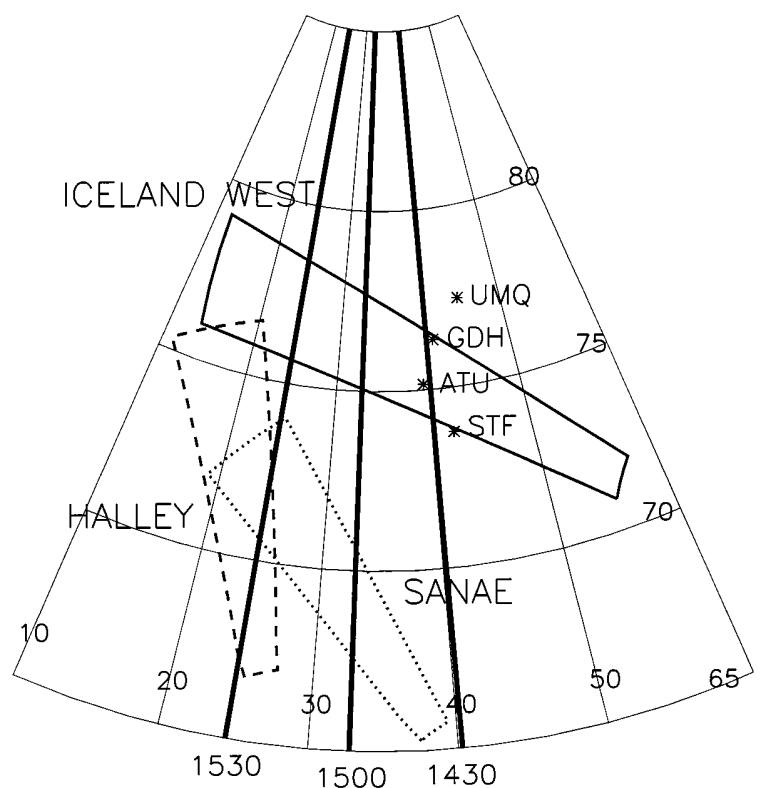

Fig. 1. Map showing the fields-of-view of the high-resolution beams from the three radars used in this study. Iceland West is shown as a bold line, Halley as a dashed line and Sanae as a dotted line. The fieldsof-view contain only the range gates where backscatter was observed during the interval studied. The fields-of-view of the Southern Hemisphere radars (Halley and Sanae) have been mapped to equivalent positions in the Northern Hemisphere. The four Greenland magnetometer stations used in this study are denoted by asterisks. The three solid vertical lines represent the location of magnetic local noon at 1430,1500 and $1530 \mathrm{UT}$

resulting from the choice of high-resolution beams. The three high-resolution beams at Iceland West observed backscatter over a wide longitudinal extent but a narrow latitudinal extent. In contrast, at Halley the highresolution beams observed backscatter over a wide latitudinal extent but a narrow longitudinal extent. Also shown in Fig. 1 is the movement of magnetic local noon in the time interval of study illustrating the proximity of all the radars to magnetic local noon. At the time of the event, the high-time resolution beams at all of the radars were observing some part of the cusp region, as defined in the radar observations by high spectral width values $(>200 \mathrm{~m} / \mathrm{s})$ (Baker et al., 1995). The Southern Hemisphere radars also observed the region just equatorward of the cusp defined by lower spectral width values $(<50 \mathrm{~m} / \mathrm{s})$. Figure 1 also shows the location of four of the Danish Meteorological Institute (DMI) array of magnetometers along the west coast of Greenland. Data from these magnetometers are also presented here.

\section{Observations}

\subsection{Solar wind}

During the interval presented, the WIND spacecraft was located $\sim 210 R_{E}$ upstream of the Earth. Figure 2 presents the three components of the IMF in GSM coordinates for the interval 1300 UT to 1530 UT on 8 May, 1998. Also shown is the solar wind dynamic

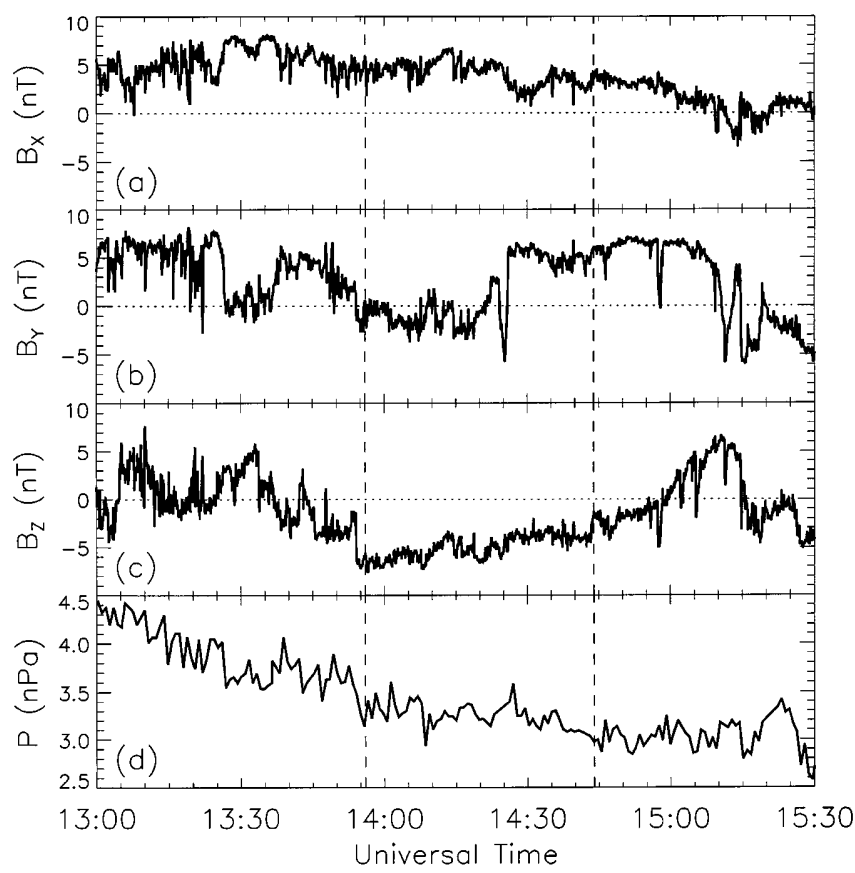

Fig. 2a-d. WIND measurements of the interplanetary magnetic field components a $B_{x}$, b $B_{y}, \mathbf{c} B_{z}$ for the interval 1300 to 1530 UT on 8 May, 1998. d Shows the dynamic pressure variation for the same interval

pressure derived from the solar wind proton density and velocity. These data occurred a few hours after the passage of a coronal mass ejection. The centre of the interval presented in Fig. 2 is characterised by an extended period of IMF $B_{z}$ negative at which time good backscatter was recorded by the three radars employed in this study (this is accounting for the time delay between the signal observed at the spacecraft and at the Earth which will be discussed later). The interval between the two dashed lines in Fig. 2 represents the time interval studied in the remainder of this work. Two of the IMF components remained approximately constant throughout this interval; $B_{z}$ remained negative between -4 and $-7 \mathrm{nT}$ and $B_{x}$ remained positive between 2 and $5 \mathrm{nT}$. The $B_{y}$ component, however, changed from fluctuating between zero and slightly negative (between 0 and $-3 \mathrm{nT}$ ) to being clearly positive (between 5 and $6 \mathrm{nT}$ ). This transition in $B_{y}$ was also characterised by a 'blip' where the $B_{y}$ component dropped to $\sim-5 \mathrm{nT}$ for about $2 \mathrm{~min}$. There is little variation in the dynamic pressure in the interval being studied (Fig. 2d), the maximum variations being $\sim 10 \%$ of the average. It is unlikely that these small changes in pressure would have a significant effect on the ionospheric convection (e.g. Kaufmann and Konradi, 1969).

In a study comparing the timing of events in the ionosphere with those in the solar wind, the estimation of the time delay of the signals from the upstream solar wind to the magnetosphere is of crucial importance. These time delays are generally difficult to estimate accurately due to the large distance between the observations and the uncertainty concerning the evolution of the solar wind features across this distance. The accu- 
racy of the time delay estimation for this event was enhanced due to the location of the GEOTAIL spacecraft just outside the dusk bow shock. Although the GEOTAIL data were complicated by a number of bow shock crossings, the cross-correlation of the three components of the IMF with those observed by WIND yielded good correlations (correlation coefficients $\sim 0.7$ 0.8 ) in the $B_{y}$ and $B_{z}$ components for a time lag of $36 \mathrm{~min}$. The observed IMF variations would most likely have impinged on the sub-solar bow shock/magnetosheath $\sim 2-4$ min before their observation at GEOTAIL. This narrows down the uncertainty in our timing although arguably the best estimate of the timing comes from looking at the changes that the radars observe in the cusp region ionosphere. The data sets can be most accurately aligned by considering the variations expected for different IMF $B_{y}$ conditions (Greenwald et al., 1990). The 'blip' observed in $B_{y}$ is a particularly good feature to help this alignment. However, we must remember that the magnetic field variations in the magnetosheath will not be the same as in the solar wind due to processes occurring at the bow shock and within the magnetosheath itself. It is usual, however, that the gross features of the solar wind variations are apparent in the magnetosheath.

Figure 3 presents high-time resolution line-of-sight velocity data $\left(V_{l o s}\right)$ for a single beam from each of the three radars used in this study and makes a comparison to the observed variation in IMF $B_{y}$ as seen by WIND (Fig. 3a). A delay of $34 \mathrm{~min}$ is added to the WIND $B_{y}$ variation to show correspondence with the Iceland West variations (see Sect. 3.2). A series of vertical lines match the ionospheric response at each of the radars to features in the $B_{y}$ variations. These vertical lines deliniate four separate intervals of varying $B_{y}$ conditions: (1) an interval of $B_{y}<0 / B_{y} \sim 0$; (2) a transition region where $B_{y}$ changes from negative to positive; (3) a $B_{y}<0$ "blip"; and (4) an interval of $B_{y}>0$. The

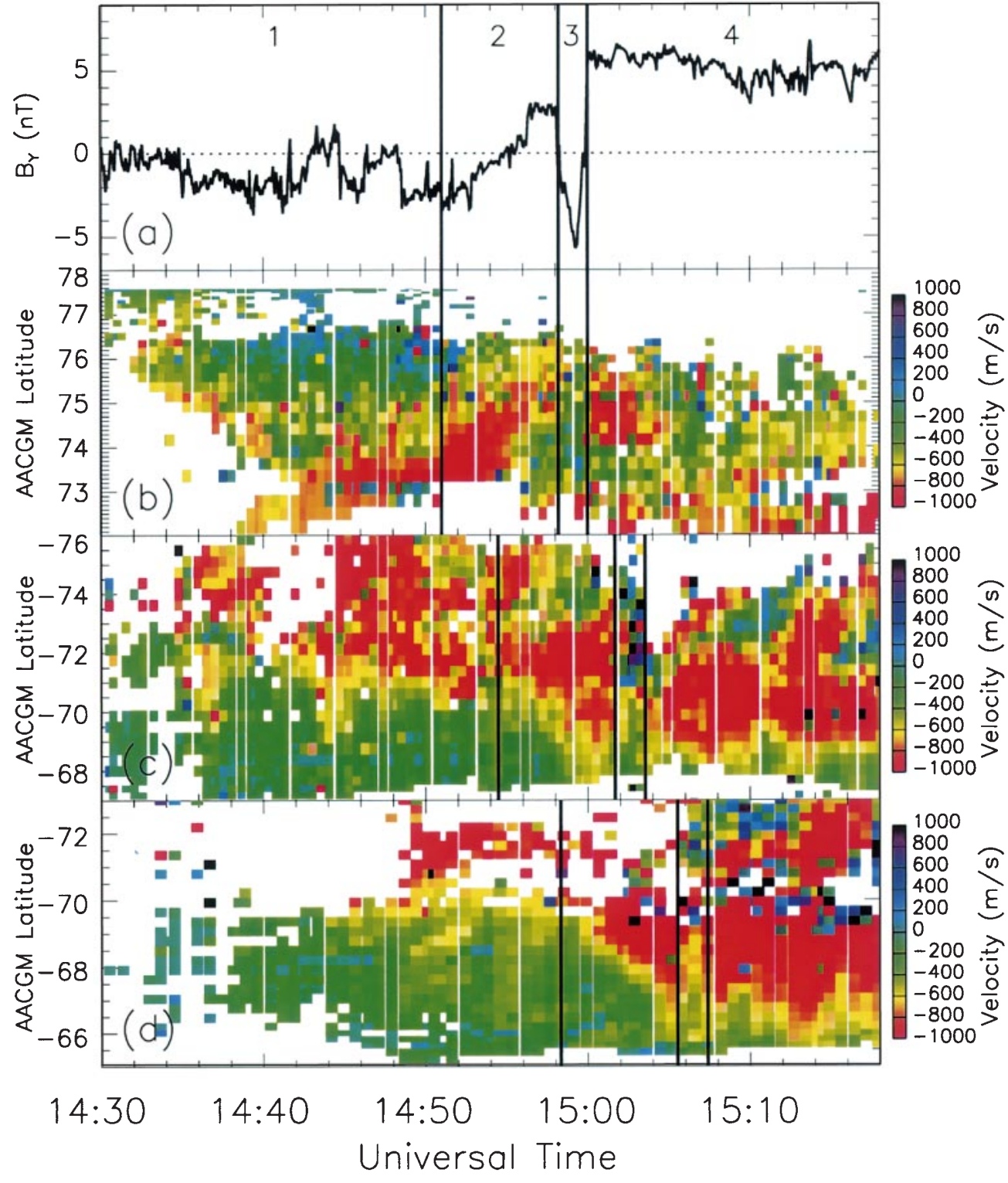

Fig. 3a-d. Comparison of a the $B_{y}$ component of the interplanetary magnetic field and the lineof-sight velocity measurements from b Iceland West beam 8, c Halley beam 4 , and d Sanae beam 5 . The $B_{y}$ data in a have been shifted by 34 min to show correspondence to the Iceland West data. The three solid vertical lines deliniate features of the $B_{y}$ variation and the corresponding responses as seen by the three radars 
corresponding variations seen by each radar are described in the following sections.

\subsection{Iceland West}

The Iceland West radar observed cusp region backscatter between 1430 and 1520 UT on 8 May, 1998. Figure $3 \mathrm{~b}$ presents the $V_{\text {los }}$ variation from beam 8 between $72^{\circ}$ and $78^{\circ}$ latitude. Positive (negative) values represent line-of-sight velocities which are towards (away from) the radar. The typical velocity error at Iceland West through this interval was in the range $50-100 \mathrm{~ms}^{-1}$ and the whole region of backscatter was characterised by high spectral width values. Figure $4 \mathrm{a}, \mathrm{b}$ presents the corresponding Northern Hemisphere velocity vectors for two 10-minute intervals of data from Iceland West and Goose Bay. The limited nature of the Goose Bay backscatter on this day has led to a sparsity of velocity vectors for these intervals. The dotted lines in Fig. $4 a, b$ represent the field-of-view of the Iceland West highresolution beams, and the bold vertical line represents the location of magnetic local noon. We justify the correspondence between the changes in $V_{\text {los }}$ (Fig. 3b) and those in $B_{y}$ (Fig. 3a) by picking out the following features of the Iceland West $V_{l o s}$ and the Northern Hemisphere velocity vector variation:

1. Between approximately 1435 and 1450 UT (interval 1) the data are characterised by high negative $V_{\text {los }}$ at the lower latitudes $\left(\sim 73-74^{\circ}\right)$ smoothly varying to low positive $V_{\text {los }}$ at the higher latitudes $\left(\sim 76-77^{\circ}\right)$. In Fig. 4a, which presents the velocity vectors for this interval, the higher latitude vectors are typically directed poleward/ eastward whilst the lower latitude vectors are typically directed poleward/westward. We interpret this change as representing the convection reversal boundary (at approximately $75^{\circ}$ ) and the pattern observed as that corresponding to the expected variation at the westward edge of the afternoon convection cell in the Northern Hemisphere for $B_{y}<0 / B_{y} \sim 0$ (Greenwald et al., 1990). Therefore we conclude that this interval matches the interval of IMF $B_{y}<0 / B_{y} \sim 0$ (interval 1) in Fig. 3a.

2. Between approximately 1451 and 1458 UT (interval 2) the data display an increase in the magnitude of

\section{NORTHERN HEMISPHERE}

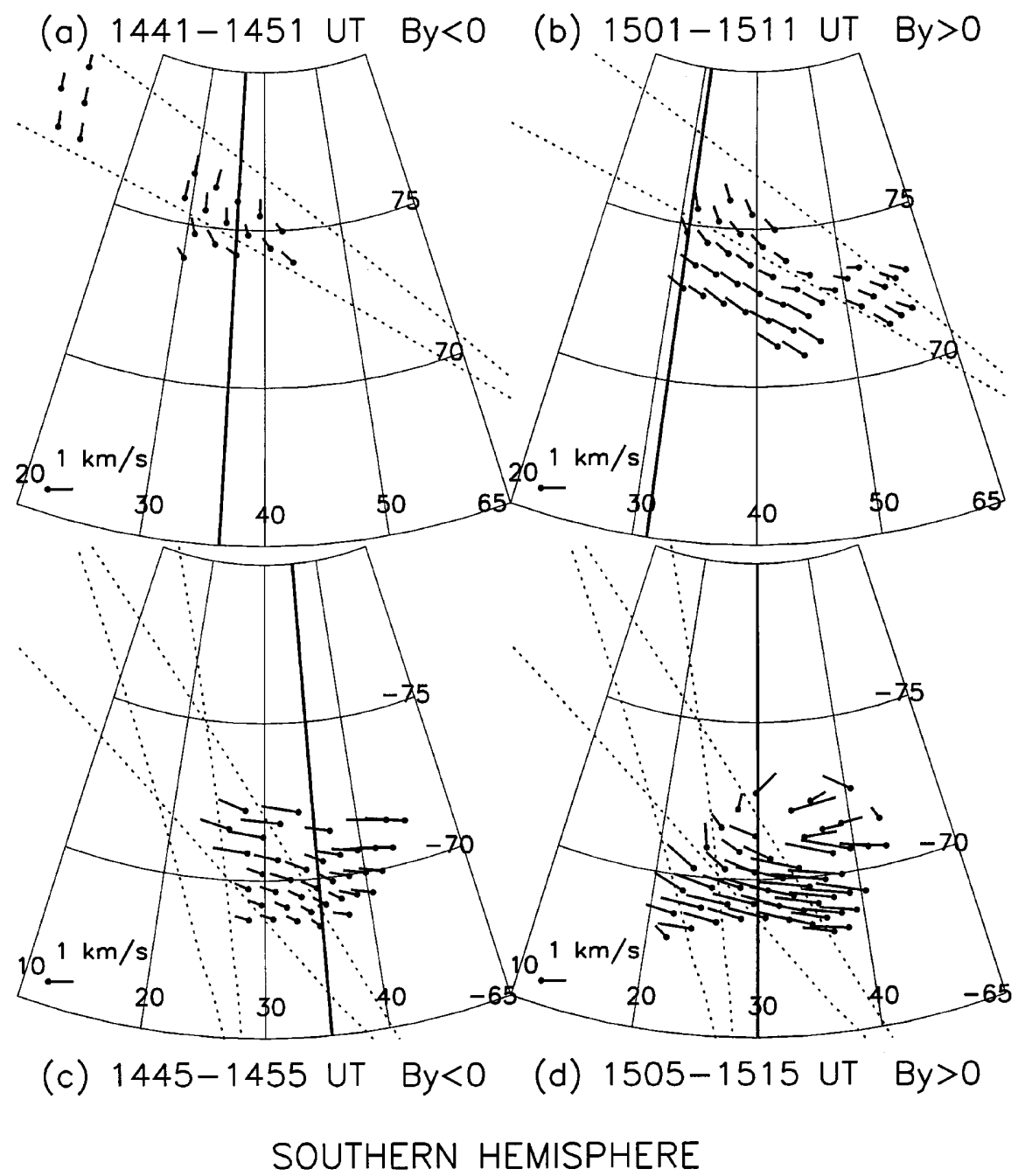

Fig. 4a-d. The velocity vector variation in the Northern and Southern Hemispheres determined from the line-of-sight velocity data from Iceland West and Goose Bay in the Northern Hemisphere and Halley and Sanae in the Southern Hemisphere. The consecutive panels represent a a 10 -min interval of negative $B_{y}$ in the Northern Hemisphere, b a 10-min interval of positive $B_{y}$ in the Northern Hemisphere, c a 10-min interval of negative $B_{y}$ in the Southern Hemisphere, and d a 10-min interval of positive $B_{y}$ in the Southern Hemisphere. The bold lines represent the location of magnetic local noon and the dotted lines encompass the highresolution beams from Iceland West in $\mathbf{a}, \mathbf{b}$, and the highresolution beams from Halley and Sanae in $\mathbf{c}$, $\mathbf{d}$ 
$V_{l o s}$ at all latitudes compared with interval 1. This increase represents the rotation of velocity vectors poleward of the convection reversal boundary from being almost perpendicular to the radar line-of-sight to being progressively more parallel to the radar line-ofsight. This transition is clearly seen between the velocity vectors in Fig. 4a, b, the resultant pattern matching that expected at the westward edge of the afternoon convection cell in the Northern Hemisphere for $B_{y}>0$ conditions (Greenwald et al., 1990). We interpret the $V_{l o s}$ variation in this interval as corresponding to the steady change from $B_{y}<0$ to $B_{y}>0$ observed in the IMF. Towards the end of interval 2, the line-of-sight velocity decreases at all latitudes. This simply indicates that the plasma velocity has rotated through the line-of-sight of the radar to a more zonal direction.

3. Between approximately 1458 and 1500 UT (interval 3) the data are characterised by a reduction in the magnitude of $V_{\text {los }}$. This reduction lasts for approximately 2 min matching the 2-min $B_{y}<0$ 'blip' observed in the IMF. After this, the $V_{l o s}$ variation with latitude returns to one similar to that observed before the reduction, matching the IMF return to $B_{y}>0$ conditions. The temporal resolution of the velocity vector maps does not allow the variations involved with this 'blip' to be studied in detail.

4. After 1500 UT (interval 4), the $V_{l o s}$ data become variable. This may be a result of the continuing expansion of the polar cap resulting in the convection reversal boundary moving equatorward of beam 8 , or it may be a consequence of the field-of-view rotating further into the afternoon convection cell. However, the velocity vectors (Fig. 4b) show that the convection pattern remains generally as expected for $B_{y}>0$ in the Northern Hemisphere and that the $V_{\text {los }}$ variations do not represent significant changes in the velocity direction. We conclude that this region corresponds well with the region of $B_{y}>0$ observed in the IMF.

\subsection{Halley}

The Halley radar observed cusp region backscatter between 1430 and 1530 UT on 8 May, 1998. Figure 3c presents the $V_{l o s}$ variation for beam 4 between $-67^{\circ}$ and $-76^{\circ}$ latitude. The typical velocity error at Halley during this interval was $\sim 0-50 \mathrm{~ms}^{-1}$ at lower latitudes and $\sim 50-150 \mathrm{~ms}^{-1}$ at higher latitudes, the boundary following closely that between the low and high spectral width regions at $\sim 70^{\circ}-72^{\circ}$. Figure $4 \mathrm{c}$, d presents velocity vectors for two 10-min intervals of data from Halley and Sanae similar to those presented for the Northern Hemisphere. The dotted lines represent the field-of-view of the Halley and Sanae high-resolution beams. The majority of the vectors measured are in the sub-cusp region (equatorward of the observed spectral width and convection reversal boundaries), limiting the interpretations which can be drawn from them. Also, there are few vectors in the region of the Halley highresolution beams. However, all the velocity vector observations suggest that we are observing the after- noon convection cell, as in the Northern Hemisphere. Another noticeable feature of the Southern Hemisphere vector maps is that the velocities appear much larger than those observed in the Northern Hemisphere. This is discussed later. The intervals delineated by the solid vertical lines in Fig. 3c have been shifted to illustrate how $V_{\text {los }}$ features observed at Halley correspond to the changes in $B_{y}$. We justify this correspondence by picking out the following features of the Halley $V_{l o s}$ and the Southern Hemisphere velocity vector variation:

1. Between approximately 1435 and 1455 UT (interval 1), the data at Halley are characterised by low negative $V_{l o s}$ at the lower latitudes (equatorward of $-71^{\circ}$ to $-72^{\circ}$ ) and high negative $V_{l o s}$ at the higher latitudes (poleward of $-71^{\circ}$ to $-72^{\circ}$ ). This variation is consistent with vectors perpendicular to the beam look direction at the lower latitudes and poleward directed vectors at the higher latitudes. During this interval, the vectors (Fig. 4c) are predominantly westward propagating with an increase in velocity towards the higher latitudes. These variations are consistent with those expected in the afternoon convection cell in the Southern Hemisphere for $B_{y}<0 / B_{y} \sim 0$ (Greenwald et al., 1990). The limited vector coverage does not allow us to observe the poleward turning of the vectors expected at the western edge of the field-of-view and at higher latitudes.

2. Between approximately 1455 and 1502 UT (interval 2), the data display a smooth increase in $V_{l o s}$ towards the lower latitudes and a decrease in $V_{\text {los }}$ at the higher latitudes. This most likely represents the formation of the convection reversal boundary, expected for IMF $B_{y}>0$ conditions in the afternoon convection cell in the Southern Hemisphere (Greenwald et al., 1990). The largest negative velocities most likely represent the poleward velocity at the boundary at $\sim-72^{\circ}$.

3. Between approximately 1502 and 1504 UT (interval 3 ), the data show an abrupt reversal in the line-of-sight flow at higher latitudes and a reduction in the flow at lower latitude. This change lasts for approximately $2 \mathrm{~min}$ matching the 2-min $B_{y}<0$ 'blip' observed in the IMF. After this interval, the $V_{l o s}$ variation returns to one similar to that observed before the change matching the IMF return to $B_{y}>0$ conditions. The resolution of the vector velocity maps does not allow the changes associated with the 'blip' to be observed in detail. The reason for the reversal in the $V_{l o s}$ variation is unclear but must represent a disturbance in the flow resulting from the sharp change in $B_{y}$. However, the temporal resolution of the radars cannot resolve such short-lived features.

4. After 1504 UT (interval 4), the $V_{l o s}$ variation is consistent with a convection reversal boundary at approximately $-71^{\circ}$ (Fig. 4d) and a convection pattern consistent with the westward edge of the afternoon convection cell in the Southern Hemisphere for IMF $B_{y}>0$ (Greenwald et al., 1990). There is also evidence of very high velocity flow bursts $\left(>2 \mathrm{kms}^{-1}\right.$ ) (e.g. Lockwood et al., 1995) and poleward moving forms in the flow at this time. The origin of these poleward moving forms is unclear but they may represent the ionospheric signature of flux transfer events. 
The data from Iceland West and Halley show many similarities corresponding to the observed changes in the $B_{y}$ component of the IMF. However, the corresponding features are observed about 3-4 min later in the Southern Hemisphere than in the Northern Hemisphere. The possible interpretations of this delay will be discussed later.

\subsection{Sanae}

The Sanae radar also observed cusp region backscatter between 1430 and 1530 UT on 8 May, 1998, although the latitudinal range was not as great as that observed by Halley. Figure $3 \mathrm{~d}$ presents the $V_{l o s}$ variation for Sanae beam 5 between $-65^{\circ}$ and $-73^{\circ}$ latitude. The typical velocity error at Sanae was similar to Halley. The solid vertical lines in Fig. 3d illustrate how the $V_{l o s}$ features correspond to the changes in $B_{y}$ (Fig. 3a). The variations observed at Sanae are very similar to those observed at the Halley lower latitudes (although shifted in time); the higher-latitude backscatter at Sanae is very patchy until approximately 1505 UT. The similarity to the Halley variations allows us to set the timing of the response to the $B_{y}$ changes accordingly. This highlights a further time delay of the ionospheric response at Sanae of $\sim 4$ min compared with Halley. The possible interpretations of this delay will be discussed later.

\subsection{Backscatter power variations}

The variations in backscatter power measured by the high-time resolution beams on the three radars show some interesting features (Fig. 5). Figure 5a presents the IMF $B_{y}$ variation shifted by $34 \mathrm{~min}$ as in Fig. 3a, and the solid vertical lines deliniate the four intervals of interest. Figure $5 \mathrm{~b}$ presents the backscatter power

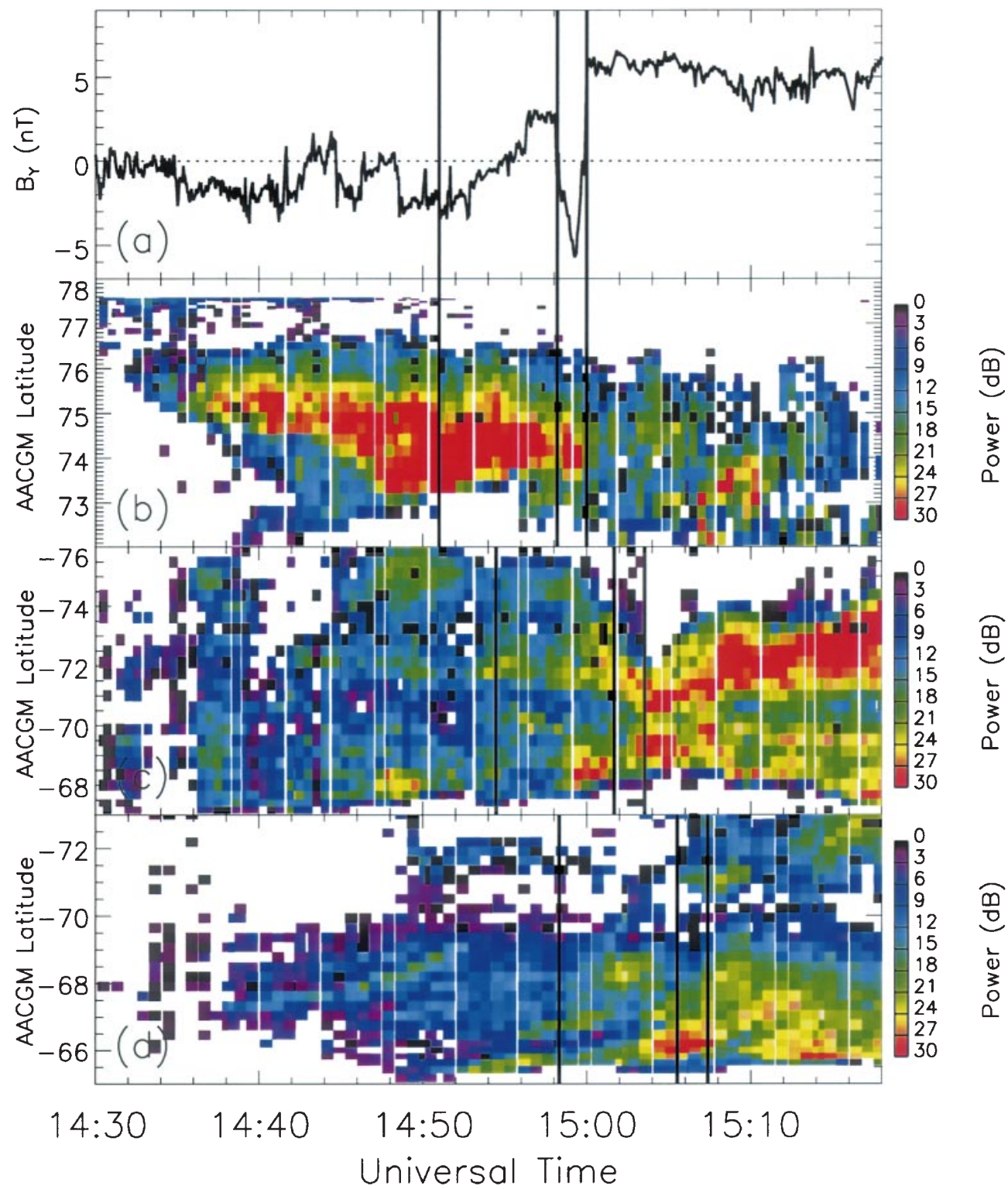

Fig. 5a-d. Comparison of a the $B_{y}$ component of the interplanetary magnetic field and the backscatter power measurements from b Iceland West beam 8 , c Halley beam 4, and d Sanae beam 5 . The $B_{y}$ data in a have been shifted by $34 \mathrm{~min}$ as in Fig. 3. The three solid vertical lines deliniate features of the $B_{y}$ variation and the corresponding responses as seen by the three radars as in Fig. 3 
variation from beam 8 of the Iceland West radar. We observe a band of high power (red) between $73^{\circ}$ and $76^{\circ}$ magnetic latitude while $B_{y}<0 / B_{y} \sim 0$. As $B_{y}$ turns positive, this band disappears and the backscatter power is predominantly low. Figure $5 \mathrm{c}$ presents the backscatter power variation from beam 4 of the Halley radar. We observe low backscatter power while $B_{y}<0 / B_{y} \sim 0$. As $B_{y}$ turns positive, we observe the formation of two bands of high backscatter power, the major one centred on $-72^{\circ}$ and a minor one between $-68^{\circ}$ and $-70^{\circ}$. Figure $5 \mathrm{~d}$ presents the backscatter power variation from beam 5 of the Sanae radar. The observations are similar to those at Halley although the higher latitude region of strong backscatter is weaker at Sanae.

We know from the velocity vector variations that the high-time resolution beams are observing the afternoon convection cell in both the Northern and Southern Hemispheres. This cell is characterised by a sharp reversal in flow (separated by the convection reversal boundary) in the magnetic local noon sector in the Northern (Southern) Hemisphere when IMF $B_{y}<0$ $\left(B_{y}>0\right)$. These conditions match the intervals where we observe the enhanced backscatter power in both hemispheres and so it seems likely that this particular configuration of the afternoon convection cell is responsible. There are two possible explanations for the regions of enhanced backscatter. The first is that we are observing the effects of the upward field-aligned currents associated with the convection reversal boundary. Either the enhanced electron precipitation associated with these field-aligned currents or the increased intensity of the field-aligned currents can lead to an increase in irregularity formation (see Tsunoda, 1988, for a review of ionospheric irregularity formation). However, the Halley (and Sanae) results suggest two regions of enhanced backscatter, the larger of which appears slightly poleward of the convection reversal boundary location suggested by the flow velocity variations. Another explanation is that the enhancement in irregularities is a result of a ridge of enhanced $F$-region plasma which occurs in the afternoon sector due to the oppositely directed convection and corotation electric fields (e.g. Pinnock et al., 1995). This could account for both enhancements as an enhancement would be observed twice in the same beam, once in the afternoon cell return flow at low latitude and again at higher latitudes as the throat flow region carried the enhancement poleward and duskward (see Fig. 7 of Pinnock et al., 1995). The enhanced backscatter power then arises from either improved HF propagation (greater spread of vertical ray angles will achieve orthogonality) or intense irregularity formation on the edges of the enhancement i.e. larger $\nabla N_{e}$.

\subsection{Greenland magnetometers}

Figure 6a-d presents the H-component (geomagnetic north-south) magnetic field variations measured on the ground by the four Greenland magnetometers whose locations are detailed in Fig. 1. Three of the stations are

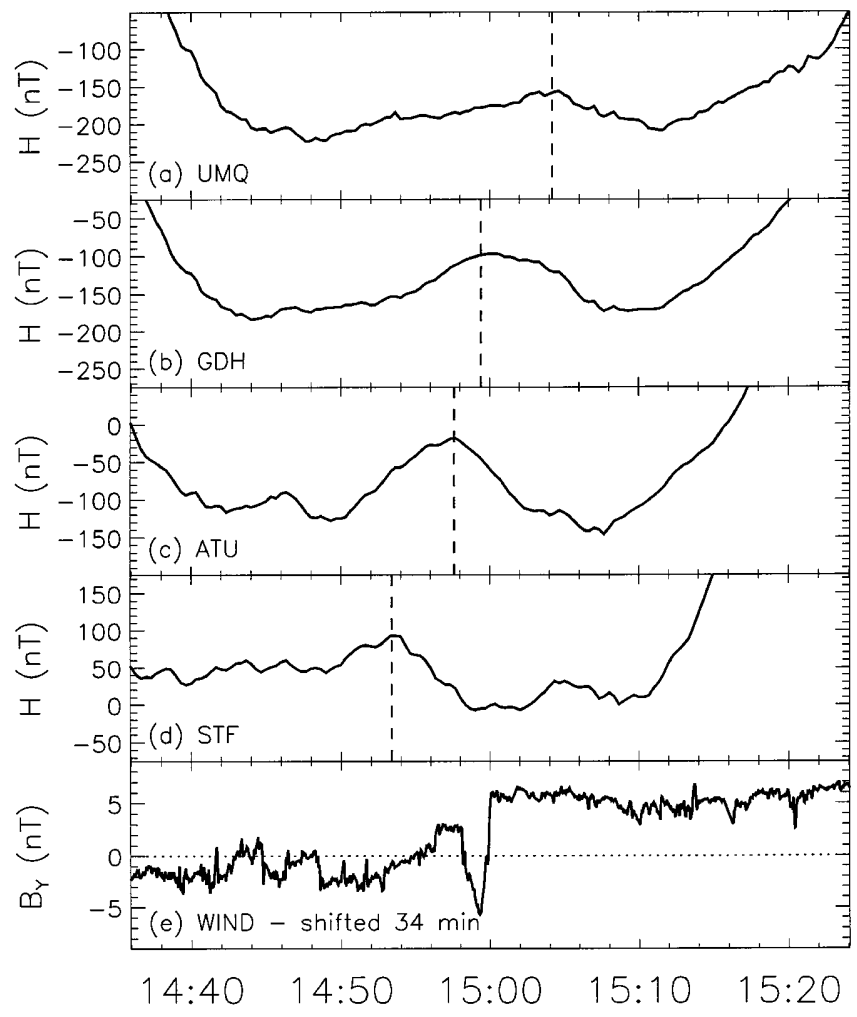

Fig. 6a-e. The H-component magnetic field variation as seen by four stations from the Greenland magnetometer chain a UMQ, b GDH, c ATU, and d STF, for the interval of interest. e Presents the $B_{y}$ variation as observed by WIND shifted by $34 \mathrm{~min}$ as in Fig. 3

to be found within the Iceland West high-resolution field-of-view; one of these (ATU) is within the beam 8 field-of-view. Figure $6 \mathrm{e}$ presents the $B_{y}$ component of the IMF shifted by $34 \mathrm{~min}$ as in Fig. 3. Figure 6 highlights with a dashed line a peak that occurs in the $\mathrm{H}$-component variation close to the switch in the shifted $B_{y}$ variation. This peak occurs first at the lower latitude station and then propagates poleward, reducing in amplitude in the process. If this peak is related to the change in $B_{y}$, it could represent the poleward propagation of the ionospheric response away from the convection reversal boundary. This feature is moving poleward at approximately $600-700 \mathrm{~ms}^{-1}$ which is very similar to the magnitude of the velocity vectors observed in the Northern Hemisphere. The peak at STF (Fig. 6d) occurs before the $B_{y}$ change in the time-shifted $B_{y}$ variation. This is probably a consequence of the 34-min time shift being chosen to coincide with the change seen in the Iceland West radar (beam 8) which is poleward of this station.

This observation has parallels with that of poleward progressing geomagnetic perturbations by Stauning et al. (1995). They correlated similar H-component perturbations with variations in IMF $B_{y}$ and suggested that they resulted from poleward progressing ionospheric Hall current systems related to the field-aligned current variations associated with the $B_{y}$ changes. Our observations of a positive enhancement in the $\mathrm{H}$ component is consistent with a $B_{y}$ change from negative 
to positive. Stauning et al. (1995) observed their Hcomponent variations in the same four Greenland magnetometer stations as the present study. They estimated a time delay in the signal propagation from STF to UMQ of $\sim 11 \mathrm{~min}$ which is of the same order as the $8 \mathrm{~min}$ observed in the present study. Hence it is possible that, as in Stauning et al. (1995), this poleward progressing $\mathrm{H}$-component peak may represent a response to changes in IMF $B_{y}$. The absence of a response to the 'blip' in the magnetometer data may be a consequence of the fact that the ground magnetometer signals represent an integration across large regions of the ionosphere, and such short-lived phenomena correspond to a small spatial scale.

Figure 6 also shows that the H-component peak almost halves in magnitude between ATU and GDH. In Fig. 3b, the $V_{l o s}$ variation as measured by Iceland West beam 8 almost halves over the same latitude range. This suggests that the magnetic field variation is a result of a change in the electric field over this interval and not a change in conductivity.

\section{Discussion}

Most of the SuperDARN radar observations presented here can be understood using the well-established framework which describes the effect of IMF $B_{y}$ on dayside convection (e.g. Heelis, 1984; Greenwald et al., 1990). The changes in convection that are observed are consistent with previous observations and this gives us confidence in the techniques we have used and in the timing of the ionospheric response in both the Northern and Southern Hemispheres. The conjugate radar observations have highlighted a time delay in the ionospheric response between the two hemispheres to changes in IMF $B_{y}$. There are three possible interpretations for this delay: (1) the Alfvén wave signal associated with the change in $B_{y}$ reaches both ionospheres at approximately the same time and the delay is due to a difference in the propagation time from the point of arrival in the ionosphere to the observation region; (2) the dominant merging region on the magnetopause is much closer to the Northern Hemisphere ionosphere due to the dipole tilt of the magnetosphere and the orientation of $B_{x}$ during this interval (e.g. Heelis, 1984) and so the Alfvén wave propagation time is very different to the two ionospheres; or (3) a combination of these.

The first time delay to consider is that of $\sim 3-4 \mathrm{~min}$ observed between Iceland West and Halley. In order to assess the importance of interpretation (1), we need to have some knowledge of where the radar fields-of-view are located with respect to the merging gap i.e. the ionospheric footprint of the reconnection X-line. This represents the first point of arrival of the Alfvén wave signal from the reconnection location and marks the start of any change in the ionospheric convection flow (e.g. Lockwood, 1997). In Fig. 4a, b, the presence of poleward velocity vectors in the Iceland West highresolution beam field-of-view suggests that these beams are observing the merging gap at the westward edge of the afternoon convection cell in the Northern Hemisphere. Although the velocity vector coverage in the Halley high-resolution beams is limited, the presence of poleward directed vectors in Fig. 4d suggests that the Halley beams are also observing the merging gap at the westward edge of the afternoon convection cell in the Southern Hemisphere. The location of the merging gap will move in azimuth as IMF $B_{y}$ changes (Cowley et al., 1991). However, it generally has a local time extent of at least a couple of hours and it appears likely that we are observing some part of the merging gap in both hemispheres over the interval of interest especially as IMF $B_{y}$ values are of modest magnitude. Therefore we conclude that interpretation (1) is not the major contributor to the Halley-Iceland West time delay.

In order to assess interpretation (2), we need to have some idea of the location of the magnetopause reconnection site. Figure 7 presents a schematic diagram illustrating the possible magnetic field scenario at the time of our observations. The figure is in the GSM X-Z plane, assumes IMF $B_{y} \sim 0$ and portrays the dipole tilt at this time. In the solar wind, $B_{z}$ is southward and $B_{x}$ is sunward. In the magnetosheath, the IMF field lines become draped around the magnetosphere. Assuming the anti-parallel merging hypothesis, the most likely reconnection site is much closer to the Northern Hemisphere ionosphere than to the Southern Hemisphere ionosphere (see Fig. 7). The difference in field-line distance from the reconnection site to the ionosphere is $\sim 8-12 R_{E}$, i.e. $4-6 R_{E}$ above the magnetic equator (Coleman, private communication). Also, the signal propagating to the Northern Hemisphere ionosphere does not travel through the region of slowest Alfvén velocity at the magnetic equator. The difference in the Alfvén wave travel time from the reconnection site could account for the observed 3-4 min delay. This interpretation is consistent with the anti-parallel merging hypothesis and also suggests that the IMF $B_{x}$

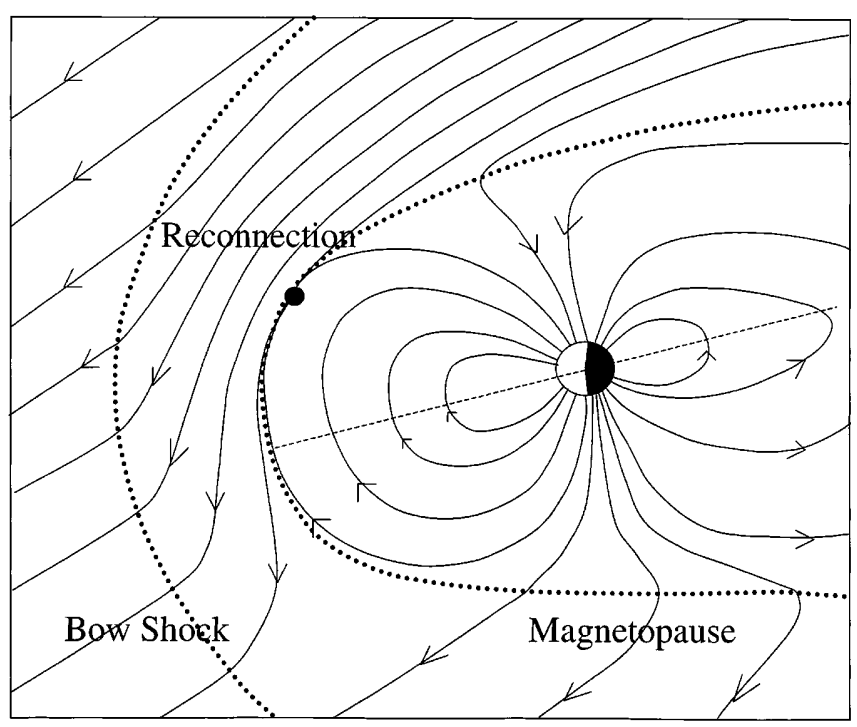

Fig. 7. Schematic diagram illustrating the possible reconnection site for this event considering the dipole tilt of the magnetosphere and the IMF orientation 
component has a significant role in solar wind-magnetosphere coupling.

Another difference between the Northern and Southern Hemisphere observations is the magnitude of the convection velocity vectors. Those observed in the Southern Hemisphere are approximately twice as big as those in the Northern Hemisphere. There are a few possible explanations for the difference in velocity magnitude. The size of the merging gap in the ionosphere has an influence on the velocity magnitude; the smaller the merging gap, the greater the flow velocity through the gap because the same potential difference is applied to both the Northern and Southern Ionospheres. Our observations do not allow us to observe the full extent of the merging gap in either hemisphere and hence we cannot make any estimate of the difference in size between the two hemispheres. The recent work of Pinnock et al. (1999) suggests that a higher-latitude cusp should have a smaller merging gap and hence larger flow velocities. This is opposite to the scenario observed (the Northern Hemisphere cusp is at higher latitudes but sees smaller flow velocities) and hence the size of the merging gap does not seem to explain the differences in flow velocity between the two hemispheres. Another factor which influences the flow velocity is the reconnection geometry. It is clear in Fig. 7 that after reconnection the magnetic tension in the southward-moving newly opened field line will be much greater than that in the northward-moving field line. Consequently, the fieldaligned currents to the Southern ionosphere will be much greater than that to the Northern ionosphere. This would lead to enhanced convection flow in the Southern Hemisphere cusp region.

The second time delay to consider is that of $\sim 4 \mathrm{~min}$ observed between the Halley and Sanae radar. This delay must correspond to a difference in the propagation time of the reconnection signal from its point of arrival in the ionosphere (the merging gap) to the two observation regions (using the model of Cowley and Lockwood, 1992). Figure 8 presents a schematic diagram illustrating a possible scenario. In Fig. 8, the highresolution Halley and Sanae regions of backscatter are

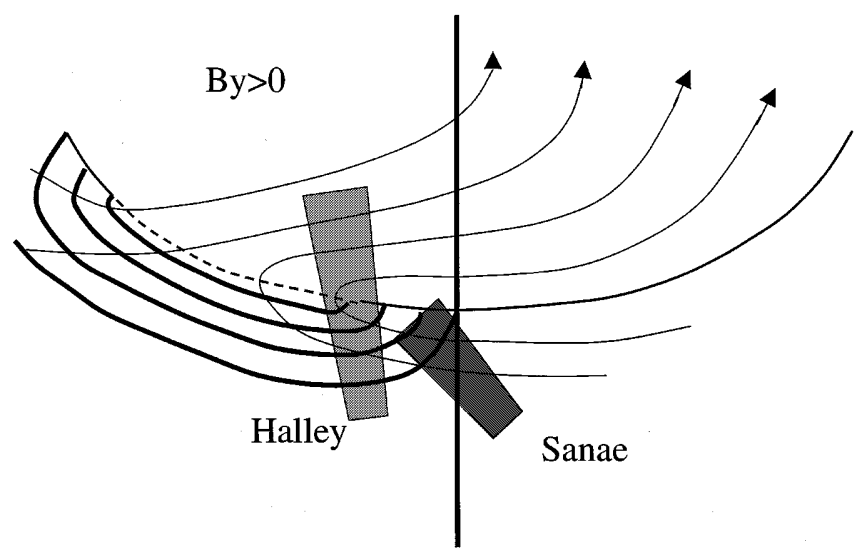

Fig. 8. Schematic diagram illustrating a possible scenario for the convection geometry in the Southern Hemisphere for $B_{y}>0$. See text for details represented by the shaded boxes, the bold vertical line represents magnetic local noon at $1500 \mathrm{UT}$, the thin lines represent the convection pattern around noon in the Southern Hemisphere for $B_{y}>0$, the dashed line represents the merging gap, and the bold lines represent the propagation of the ionospheric response away from the merging gap. Figure 4d suggests that the Halley high-resolution beams are just observing the eastern edge of the merging gap as $B_{y}$ turns positive. Detailed study of the line-of-sight velocity variations from the Halley high-time resolution beams shows no evidence of signal propagation across the Halley beams (suggesting a location in the source region). However, a clear westto-east signal propagation is observed in the Sanae hightime resolution beams (suggesting a location east of the source region). This confirms that changes in convection would be observed first by the Halley radar and later by the Sanae radar. At $-69^{\circ}$ magnetic latitude, the distance between Halley beam 4 and Sanae beam 5 is $\sim 290 \mathrm{~km}$, at $-68^{\circ}$ it is $\sim 375 \mathrm{~km}$. Assuming a time delay of $4 \mathrm{~min}$, this would suggest a propagation speed of $\sim 1.2 \mathrm{kms}^{-1}$ at $-69^{\circ}$ and $\sim 1.6 \mathrm{kms}^{-1}$ at $-68^{\circ}$. These speeds are consistent with previously observed propagation speeds outside the merging gap (e.g. Lockwood et al., 1986; Saunders et al., 1992), and this supports our interpretation of the Halley-Sanae time delay.

\section{Summary}

Using conjugate SuperDARN radar observations, we have measured a time delay in the ionospheric response to changes in IMF $B_{y}$ between the Northern and Southern Hemispheres. The Iceland West radar in the Northern Hemisphere observes changes in convection consistent with the changes in IMF $B_{y}$ about 3-4 min before the Halley radar in the Southern Hemisphere. This has been explained as being a consequence of the reconnection site on the magnetopause being closer to the Northern Hemisphere ionosphere than to the Southern Hemisphere ionosphere due to the dipole tilt of the magnetosphere and the orientation of the IMF. A further time delay of $\sim 4$ min observed in the Southern Hemisphere between Halley and Sanae has been explained as being a result of the signal propagation time from Halley (observing the merging gap) to Sanae (east of the merging gap).

Acknowledgements. We would like to thank David Walker and Ray Greenwald, the SuperDARN PIs for the Sanae and Goose Bay radars, respectively. The operation of the Stokkseyri radar is supported by the Institut National des Sciences de l'Univers (INSU) in France. The Halley radar was developed under funding from the UK Natural Environment Research Council, and the US National Science Foundation (Grant DPP-8602975). Operations are funded by the UK Natural Environment Research Council. The Sanae radar was developed under funding from the South African Department of Environmental Affairs and Tourism (DEAT), the UK Natural Environment Research Council, and the US National Science Foundation (Grant OPP-9421266). Operations are supported by DEAT. We are grateful to R. Lepping and R. Lin, principal investigators on the WIND spacecraft MFI and 3DP instruments respectively. We would also like to 
acknowledge S. Kokubun, principal investigator on the GEOTAIL spacecraft MGF instrument. We would like to thank P. Stauning and O. Rasmussen for supplying the Greenland magnetometer data. We would also like to thank the Halley engineer, Kevin O'Rourke, for all his hard work during the campaign when these observations were made.

Topical Editor M. Lester thanks S.W.H. Cowley and P.E. Sandholt for their help in evaluating this paper.

\section{References}

Baker, K. B., J. R. Dudeney, R. A. Greenwald, M. Pinnock, P. T. Newell, A. S. Rodger, N. Mattin, and C.-I. Meng, HF radar signatures of the cusp and low-latitude boundary layer, $J$. Geophys. Res., 100, 7671, 1995.

Cowley, S. W. H., Magnetospheric asymmetries associated with the Y-component of the IMF, Planet. Space Sci., 29, 79, 1981.

Cowley, S. W. H., and M. Lockwood, Excitation and decay of solar wind driven flows in the magnetosphere-ionosphere system, Ann. Geophysicae, 10, 103, 1992.

Cowley, S. W. H., J. P. Morelli, and M. Lockwood, Dependence of convective flows and particle precipitation in the high-latitude dayside ionosphere on the $\mathrm{X}$ and $\mathrm{Y}$ components of the interplanetary magnetic field, J. Geophys. Res., 96, 5557, 1991.

Crooker, N. U., Dayside merging and cusp geometry, J. Geophys. Res., 84, 951, 1979.

Etemadi, A., S. W. H. Cowley, M. Lockwood, B. J. I. Bromage, D. M. Willis, and H. Lühr, The dependence of high-latitude dayside ionospheric flows on the north-south component of the IMF. A high-time resolution correlation analysis using EISCAT "POLAR" and AMPTE UKS and IRM data, Planet. Space Sci., 36, 471, 1988.

Freeman, M. P., C. J. Farrugia, L. F. Burlaga, M. R. Hairston, M. E. Greenspan, J. M. Ruohoniemi, and R. P. Lepping, The interaction of a magnetic cloud with the Earth: Ionospheric convection in the Northern and Southern Hemispheres for a wide range of quasi-steady interplanetary magnetic field conditions, J. Geophys. Res., 98, 7633, 1993.

Friis-Christensen, E., Y. Kamide, A. D. Richmond, and S. Matsushita, Interplanetary magnetic field control of high-latitude electric fields and currents determined from Greenland magnetometer chain, J. Geophys. Res., 90, 1325, 1985.

Greenwald, R. A., K. B. Baker, J. M. Ruohoniemi, J. R. Dudeney, M. Pinnock, N. Mattin, J. M. Leonard, and R. P. Lepping, Simultaneous conjugate observations of dynamic variations in high-latitude dayside convection due to changes in IMF $B_{y}, J$. Geophys. Res., 95, 8057, 1990.

Greenwald, R. A., K. B. Baker, J. R. Dudeney, M. Pinnock, T. B. Jones, E. C. Thomas, J.-P. Villain, J.-C. Cerisier, C. Senior, C. Hanuise, R. D. Hunsucker, G. Sofko, J. Koehler, E. Nielsen, R. Pellinen, A. D. M. Walker, N. Sato, and H. Yamagishi, DARN/ SuperDARN: A global view of the dynamics of high-latitude convection, Space Sci. Rev., 71, 761, 1995.

Heelis, R. A., The effects of interplanetary magnetic field orientation on dayside high-latitude ionospheric convection, J. Geophys. Res., 89, 2873, 1984.

Heppner, J. P., and N. C. Maynard, Empirical high-latitude electric field models, J. Geophys. Res., 92, 4467, 1987.

Kaufmann, R. L., and A. Konradi, Explorer 12 magnetopause observations: Large-scale nonuniform motion, J. Geophys. Res., 74, 3609, 1969.

Lockwood, M., Relationship of dayside auroral precipitations to the open-closed separatrix and the pattern of convective flow, $J$. Geophys. Res., 102, 17,475, 1997.

Lockwood, M., and S. W. H. Cowley, Comment on "A statistical study of the ionospheric convection response to changing interplanetary magnetic field conditions using the assimilative mapping of ionospheric electrodynamics technique" by A.J. Ridley et al., J. Geophys. Res., 104, 4387, 1999.
Lockwood, M., A. P. van Eyken, B. J. I. Bromage, D. M. Willis, and S. W. H. Cowley, Eastward propagation of a plasma convection enhancement following a southward turning of the interplanetary magnetic field, Geophys. Res. Lett., 13, 72, 1986.

Lockwood, M., S. W. H. Cowley, P. E. Sandholt, and U. P. Lovhaug, Causes of plasma flow bursts and dayside auroral transients: an evaluation of two models invoking reconnection pulses and changes in the $\mathrm{Y}$ component of the magnetosheath field, J. Geophys. Res., 100, 7613, 1995.

Moses, J. J., G. L. Siscoe, N. U. Crooker, and D. J. Gorney, IMF $B_{y}$ and day-night conductivity effects in the expanding polar cap convection model, J. Geophys. Res., 92, 1193, 1987.

Pinnock, M., A. S. Rodger, and F. T. Berkey, High-latitude $F$ region electron concentration measurements near noon: a case study, J. Geophys. Res., 100, 7723, 1995.

Pinnock, M., A. S. Rodger, K. B. Baker, G. Lu, and M. Hairston, Conjugate observations of the dayside reconnection electric field: a GEM boundary layer campaign, Ann. Geophysicae, 17, 443, 1999.

Reiff, P. H., and J. L. Burch, IMF $B_{y}$-dependent plasma flow and birkeland currents in the dayside magnetosphere 2. A global model for northward and southward IMF, J. Geophys. Res., 90, 1595, 1985.

Rich, F. J., and M. Hairston, Large-scale convection patterns observed by DMSP, J. Geophys. Res., 99, 3827, 1994.

Ridley, A. J., G. Lu, C. R. Clauer, and V. O. Papitashvili, A statistical study of the ionospheric convection response to changing interplanetary magnetic field conditions using the assimilative mapping of ionospheric electrodynamics technique, J. Geophys. Res., 103, 4023, 1998.

Ridley, A. J., G. Lu, C. R. Clauer, and V. O. Papitashvili, Reply, J. Geophys. Res., 104, 4393, 1999.

Ruohoniemi, J. M., and R. A. Greenwald, Statistical patterns of high-latitude convection obtained from Goose Bay HF radar observations, J. Geophys. Res., 101, 21,743, 1996.

Ruohoniemi, J. M., and R. A. Greenwald, The response of high latitude convection to a sudden southward IMF turning, Geophys. Res. Lett., 25, 2913, 1998.

Ruohoniemi, J. M., R. A. Greenwald, K. B. Baker, and J.-P. Villain, Drift motions of small-scale irregularities in the high-latitude $F$ region: an experimental comparison with plasma drift motions, J. Geophys. Res., 92, 4553, 1987.

Saunders, M. A., M. P. Freeman, D. J. Southwood, S. W. H. Cowley, M. Lockwood, J. C. Samson, C. J. Farrugia, and T. J. Hughes, Dayside ionospheric convection changes in response to long-period interplanetary magnetic field oscillations: determination of the ionospheric phase velocity, J. Geophys. Res., 97, 19,373, 1992.

Senior, C., D. Fontaine, G. Caudal, D. Alcaydé, and J. Fontanari, Convection electric fields and electrostatic potential over $61^{\circ}<\lambda<72^{\circ}$ invariant latitude observed with the European incoherent scatter facility, 2, Statistical results, Ann. Geophysicae, 8, 257, 1990.

Stauning, P., C. R. Clauer, T. J. Rosenberg, E. Friis-Christensen, and R. Sitar, Observations of solar-wind-driven progression of interplanetary magnetic field $B_{y}$-related dayside ionospheric disturbances, J. Geophys. Res., 100, 7567, 1995.

Smith, M. F., and M. Lockwood, Earth's magnetospheric cusps, Rev. Geophys., 34, 233, 1996.

Todd, H., B. J. I. Bromage, S. W. H. Cowley, M. Lockwood, A. P. van Eyken, and D. M. Willis, EISCAT observations of bursts of rapid flow in the high latitude dayside ionosphere, Geophys. Res. Lett., 13, 909, 1986.

Tsunoda, R. T., High-latitude F-region irregularities: a review and synthesis, Rev. Geophys., 26, 719, 1988.

Villain, J.-P., G. Caudal, and C. Hanuise, A SAFARI-EISCAT comparison between the velocity of $\mathrm{F}$ region small-scale irregularities and the ion drift, J. Geophys. Res., 90, 8433, 1985.

Weimer, D. R., Models of high-latitude electric potentials derived with a least error fit of spherical harmonic coefficients, $J$. Geophys. Res., 100, 19,595, 1995. 